
NATIONAL INSTITUTE OF STANDARDS \&

TECHNOLOGY

Research Information Center

Gaithersburg, MD 2089 



\section{IR 89-3922}

\section{CANCELLED}

\section{UNAVAILABLE FOR BINDING}





\section{IR 89-3923}

\section{CANCELLED}

\section{UNAVAILABLE FOR BINDING}



NISTIR 89-3924

\section{NEAR-FIELD GAIN \\ OF PYRAMIDAL HORNS \\ FROM 18 TO $40 \mathrm{GHz}$}

David A. Hill

Richard L. Ehret

National Institute of Standards and Technology

U.S. Department of Commerce

Boulder, Colorado 80303-3328

November 1989 

NISTIR 89-3924

\section{NEAR-FIELD GAIN \\ OF PYRAMIDAL HORNS \\ FROM 18 TO $40 \mathrm{GHz}$}

David A. Hill

Richard L. Ehret

Electromagnetic Fields Division

Center for Electronics and Electrical Engineering

National Engineering Laboratory

National Institute of Standards and Technology

Boulder, Colorado 80303-3328

November 1989

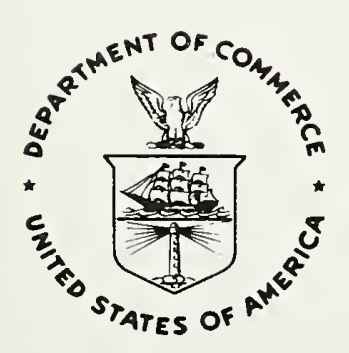



CONTENTS

Page

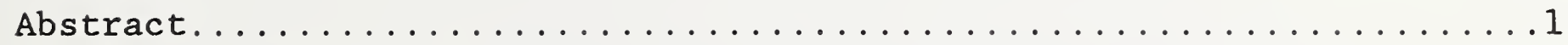

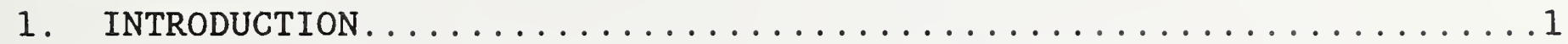

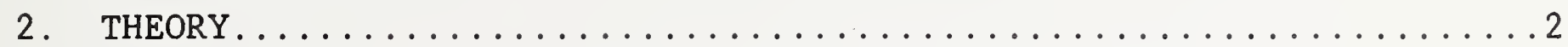

3. MEASUREMENTS ................................ .

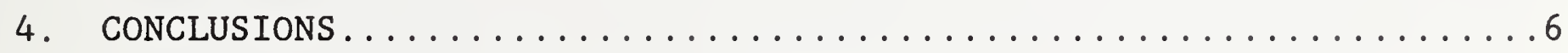

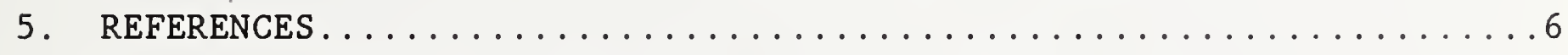



David A. Hill and Richard L. Ehret

Electromagnetic Fields Division National Institute of Standards and Technology Boulder, CO 80303

Generating a standard electromagnetic field requires knowledge of the gain of the transmitting antenna. Using the two-antenna method, we have measured the near-field gain of pyramidal horns at frequencies from 18 to $40 \mathrm{GHz}$. The discrepancy between the measured and theoretical near-field gain is typically within $\pm 0.3 \mathrm{~dB}$ for distances from 0.5 to $4 \mathrm{~m}$ from the horn aperture. An accurate laser alignment of the horns was necessary to obtain this level of agreement.

Key words: anechoic chamber; electric field; near-field gain; pyramidal horn; two-antenna method.

\section{INTRODUCTION}

Anechoic chambers are currently in use for a variety of indoor antenna measurements, electromagnetic interference (EMI) measurements, and electromagnetic compatibility (EMC) measurements. The main requirement is that a transmitting antenna located within the chamber generate a known field throughout a volume of sufficient size to perform antenna measurements.

The methodology for standard electromagnetic field measurements using the National Institute of Standards and Technology (NIST) anechoic chamber has been described in previous publications [1-3]. Measurements in an anechoic chamber are usually performed in the near field of a standard transmitting antenna, and for frequencies above $450 \mathrm{MHz}$ NIST uses a series of pyramidal horns for transmitting antennas. In this report we compare theoretical and measured near-field gains of pyramidal horns for frequencies from 18 to $40 \mathrm{GHz}$. The theory [4,5] and measurement techniques [1-3] are the same as those previously used at NIST at lower frequencies (below 18 $\mathrm{GHz}$ ). 
In section 2 we review the theory for the near-field gain of pyramidal horns, and in section 3 we present measured results for the near-field gain for frequencies from 18 to $40 \mathrm{GHz}$. The good agreement between the two indicates that the NIST anechoic chamber performs well over this frequency range.

2. THEORY

The geometry of a pyramidal horn is shown in figure 1 . The width and height of the rectangular aperture are $a$ and $b$, and the slant lengths are $\ell_{E}$ and $\ell_{H}$. The near-field gain of pyramidal horns can be derived either in terms of the electric field on the horn axis [4,5] or in terms of the power transfer between a pair of identical horns [6]. We choose the electric field derivation because it is more relevant to our application of generating a standard electric field and because it involves simpler mathematical functions.

Jull's expression for the near field gain $G$ is $[4,5]$

$$
G=\frac{32 a b}{\pi \lambda^{2}} R_{E} R_{H}
$$

where $\lambda$ is the free space wavelength and $R_{E}$ and $R_{H}$ include the gain reduction due to the $\mathrm{E}$ and $\mathrm{H}$ plane flare of the horn as well as the effect of finite range. The gain reduction factors are

$$
\begin{aligned}
& R_{E}=\frac{C^{2}(w)+s^{2}(w)}{w^{2}}, \\
& R_{H}=\frac{\pi^{2}\left[[C(u)-C(v)]^{2}+[S(u)-s(v)]^{2}\right]}{4(u-v)^{2}},
\end{aligned}
$$

where $\mathrm{w}=\mathrm{b} /\left(2 \lambda \ell_{\mathrm{E}}^{\prime}\right)^{1 / 2}$, 


$$
\begin{aligned}
& u_{v}=\frac{1}{a}\left(\lambda \ell_{H}^{\prime} / 2\right)^{1 / 2} \pm a /\left(2 \lambda \ell_{H}\right)^{1 / 2}, \\
& \ell_{E}^{\prime}=\frac{d l_{E}}{d+l_{E}}, \quad \ell_{H}^{\prime}=\frac{d l_{H}}{d+\ell_{H}},
\end{aligned}
$$

and $d$ is the on-axis distance from the aperture plane. The Fresnel integrals $C$ and $S$ are defined as

$$
C(w)-j S(w)=\int_{0}^{w} \exp \left(-j \pi t^{2} / 2\right) d t
$$

In our computer program for (1)-(3), we have used the approximations of Boersma [7] to compute the Fresnel integrals, and we have checked our results with Jull's curves and tables for $R_{E}$ and $R_{H}[4,5]$. Larsen and Ries [8] have derived polynomial fits for $R_{E}$ and $R_{H}$ that are easy to compute, but these polynomial fits are not accurate for large values of $w$ and $u$. Consequently, we use the Fresnel integral formulation in (1)-( 3 ) because they have no such limitation.

In Jull's derivation of $\mathrm{R}_{\mathrm{E}}$ and $\mathrm{R}_{\mathrm{H}}$, he included quadratic phase terms in the evaluation of the aperture integration, but neglected cubic and higherorder terms. For the cubic terms to be small, the following inequality must be satisfied

$$
\frac{k\left(a^{2}+b^{2}\right)^{2}}{128 d^{3}} \ll 1
$$

where $k=2 \pi / \lambda$. For given horn dimensions and frequency, (4) places the following requirement on the range $d$

$$
d>\left[\frac{k\left(a^{2}+b^{2}\right)^{2}}{128}\right]^{1 / 3}
$$


Similarly, Jull neglected quadratic amplitude terms which means that the following inequality must be satisfied

$$
\frac{a^{2}+b^{2}}{8 d^{2}}<1
$$

For given horn dimensions, (6) places the following requirement on d

$$
d \gg\left[\left(a^{2}+b^{2}\right) / 8\right]^{1 / 2} \text {. }
$$

Taken together, (5) and (7) place a minimum value on the range d for (1)-(3) to be valid. Jull [9] has also studied the effect of edge diffraction on horn gain, but this effect tends to be fairly small.

\section{MEASUREMENTS}

Gain measurements were made in the NIST anechoic chamber using pairs of identical pyramidal horns. The gain as determined by the two-antenna method is [1]

$$
G=\frac{4 \pi d}{\lambda}\left(P_{r} / P_{t}\right)^{1 / 2}
$$

where $d$ is the distance between the horn apertures, $P_{t}$ is the net power delivered to the transmitting horn, and $\mathrm{P}_{\mathrm{r}}$ is the received power. Details of the NIST methods of power measurement have been discussed previously [1]. Normally (8) is used for the far-field gain, but here we also use (8) for the near-field gain $G$.

In figures 2-4, we show the theoretical and measured near-field gains as a function of distance $d$ for frequencies of 18,22 , and $26.5 \mathrm{GHz}$. The horn dimensions are: $a=10.43 \mathrm{~cm}, \quad b=7.88 \mathrm{~cm}, \ell_{E}=19.09 \mathrm{~cm}$, and $\ell_{\mathrm{H}}=20.34 \mathrm{~cm}$. The nominal far-field distance, $2\left(\mathrm{a}^{2}+\mathrm{b}^{2}\right) / \lambda$, is also shown 
in each figure caption, and some gain reduction is evident even at this distance. The small oscillations in the measured curves are caused by multiple reflections between the horns, and they could be smoothed out by averaging over an integer number of half wavelengths. The measured curve at $22 \mathrm{GHz}$ in figure 3 shows evidence of a more complicated interference pattern that probably involves an additional reflection. No attempt was made to determine the source of this reflection or to assess the effectiveness of the chamber absorber in this frequency range.

Further comparisons of theoretical and measured near-field gains are shown in figures 5-7 at frequencies of 26.5, 33, and $40 \mathrm{GHz}$. For these results the horn dimensions are: $a=6.89 \mathrm{~cm}, \mathrm{~b}=5.27 \mathrm{~cm}, \ell_{E}=12.73 \mathrm{~cm}$, and $\ell_{\mathrm{H}}=14.00 \mathrm{~cm}$. Small multiple reflections are again evident in the measured results, and some indication of a more complicated interference pattern appears at $40 \mathrm{GHz}$ in figure 7. An accurate laser alignment was required to obtain the agreement shown in figures 5-7. Our first attempts at these frequencies gave measured results approximately 1 dB below the theoretical gain, and rotation and movement of the antennas indicated that alignment was a problem. In the laser alignment, we sight down the waveguide of the transmitting horn to the waveguide of the receiving horn. In future calibrations of small probes or other antennas, the same method of sighting down the waveguide of the transmitting horn should work equally well.

The agreement of the theoretical and measured near-field gains generally falls within the range of 0.1 to $0.3 \mathrm{~dB}$, and this uncertainty is adequate for generation of a standard electric field strength for future antenna measurements. We cannot expect agreement any better than about $0.1 \mathrm{~dB}$ because the theory has errors of about that magnitude [9].

For the horn dimensions and frequencies in figures 2-7, the inequalities (5) and (7) yield a minimum distance $\mathrm{d}$ of about $0.5 \mathrm{~m}$. For smaller distances, the theory is not reliable. Even though the theoretical near-field gain is based on the on-axis electric field [4,5] rather than horn-to-horn transmission [6], the agreement with measured gain is roughly independent of distance for distances in the range of validity ( $>0.5 \mathrm{~m})$. For smaller distances, Jull [4] has indicated that the near-field reduction 
factors for the on-axis electric field are greater than those for horn-tohorn transmission [6].

\section{CONCLUSIONS}

Using the two-antenna method, we have measured the near-field gain of pyramidal horns at frequencies from 18 to $40 \mathrm{GHz}$. The discrepancy between the measured and theoretical near-field gain is typically within $\pm 0.3 \mathrm{~dB}$ for distances from 0.5 to $4 \mathrm{~m}$ from the horn aperture. An accurate laser alignment of the horns was necessary to obtain this level of agreement, and the same alignment method should be used for generating standard fields with horn transmitting antennas.

\section{REFERENCES}

[1] Nahman, N.H.; Kanda, M.; Larsen, E.B.; Crawford, M.L. Methodology for standard electromagnetic field measurements. IEEE Trans. Instrumentation Meas., IM-34: 490-503; 1985.

[2] Kanda, M.; Orr, R.D. Near-field gain of a horn and an open-ended waveguide: comparison between theory and experiment. IEEE Trans. Antennas Propagat., AP-35: 33-40; 1987.

[3] Kanda, M.; Driver, L.D. An isotropic electric-field probe with tapered resistive dipoles for broad-band use, $100 \mathrm{kHz}$ to $18 \mathrm{GHz}$. IEEE Trans. Microwave Theory Techniques, MTT-35: 124-130; 1987.

[4] Jul1, E.V. Finite-range gain of sectoral and pyramidal horns. Electronics Letters, 6: 680-681; 1970.

[5] Jul1, E.V. Aperture Antennas and Diffraction Theory. Stevenage: Peter Peregrinus Ltd.; 1981.

[6] Chu, T.S.; Semplak, R.A. Gain of electromagnetic horns. Bell Syst. Tech. J., 44: 527-537; 1965 .

[7] Boersma, J. Computation of Fresnel integrals. Math. Comp., 14: 380; 1960 .

[8] Larsen, E.B.; Ries, F.X. Design and calibration of the NBS isotropic electric-field monitor (EFM-5), 0.2 to $1000 \mathrm{MHz}$. Nat. Bur. Stand. (U.S.) Technical Note 1033; 1981. 
[9] Jul1, E.V. Errors in the predicted gain of pyramidal horns. IEEE Trans. Antennas Propagat., AP-21: 25-31; 1973. 


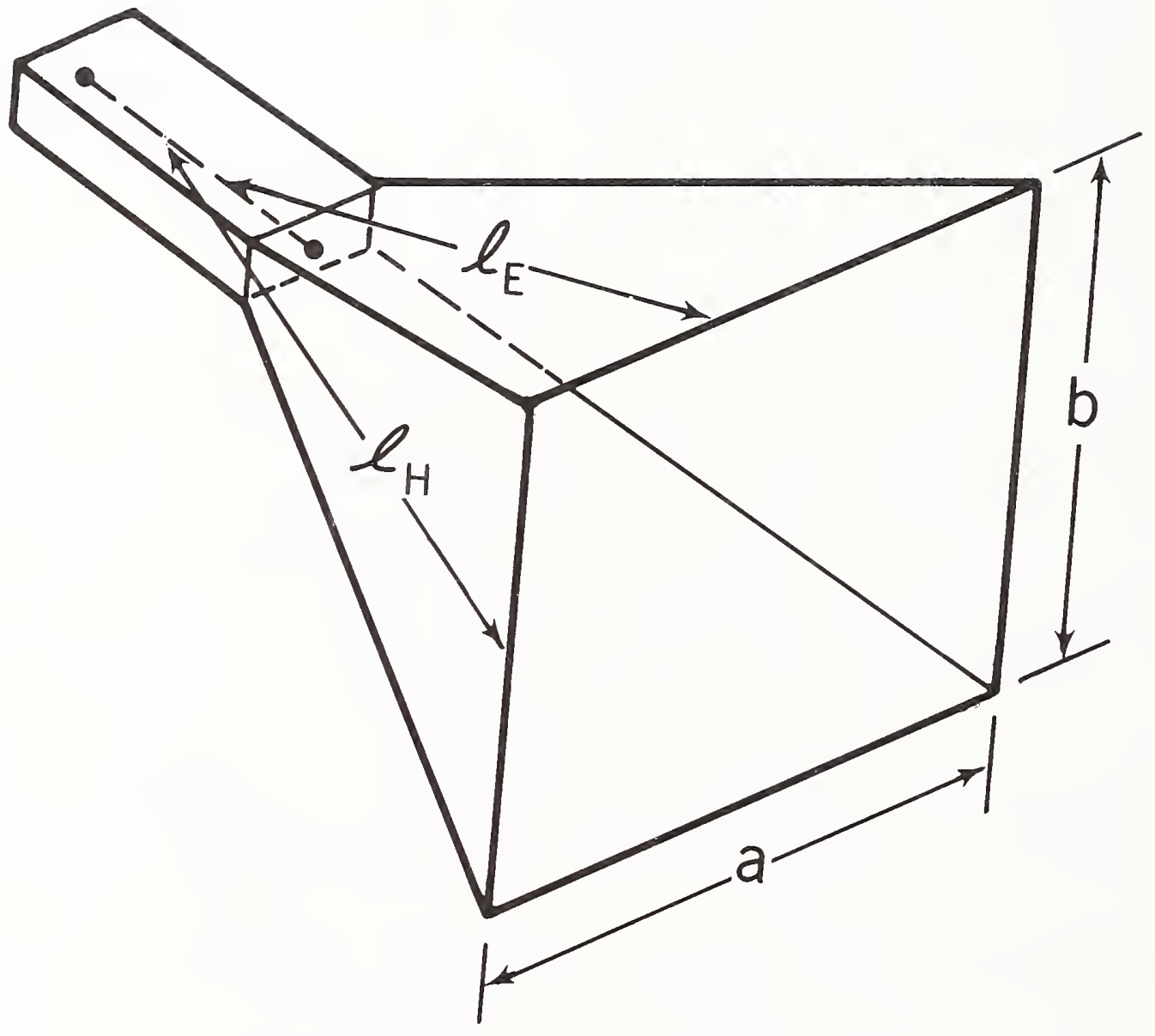

Figure 1. Geometry and dimensions of a pyramidal horn antenna. 


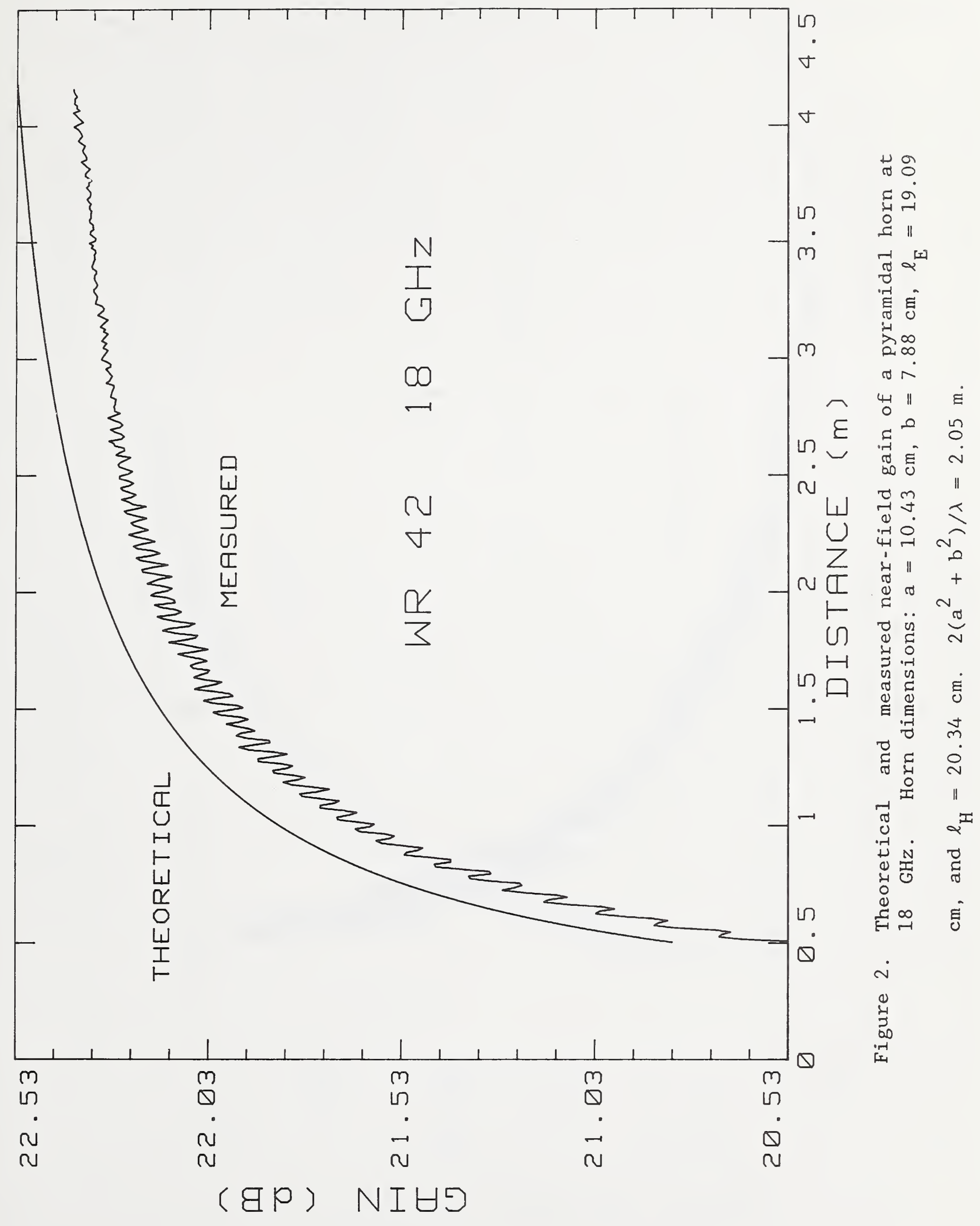




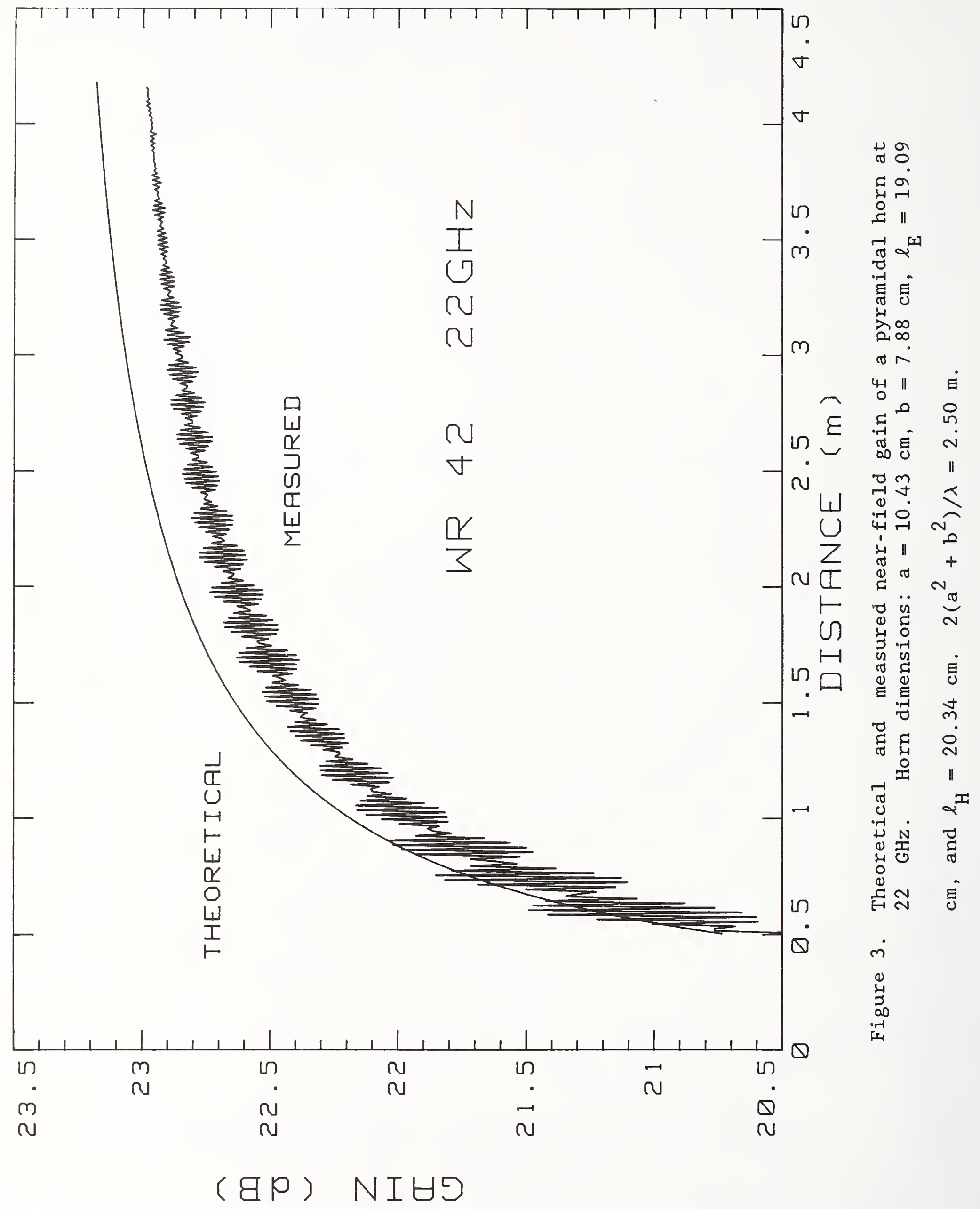




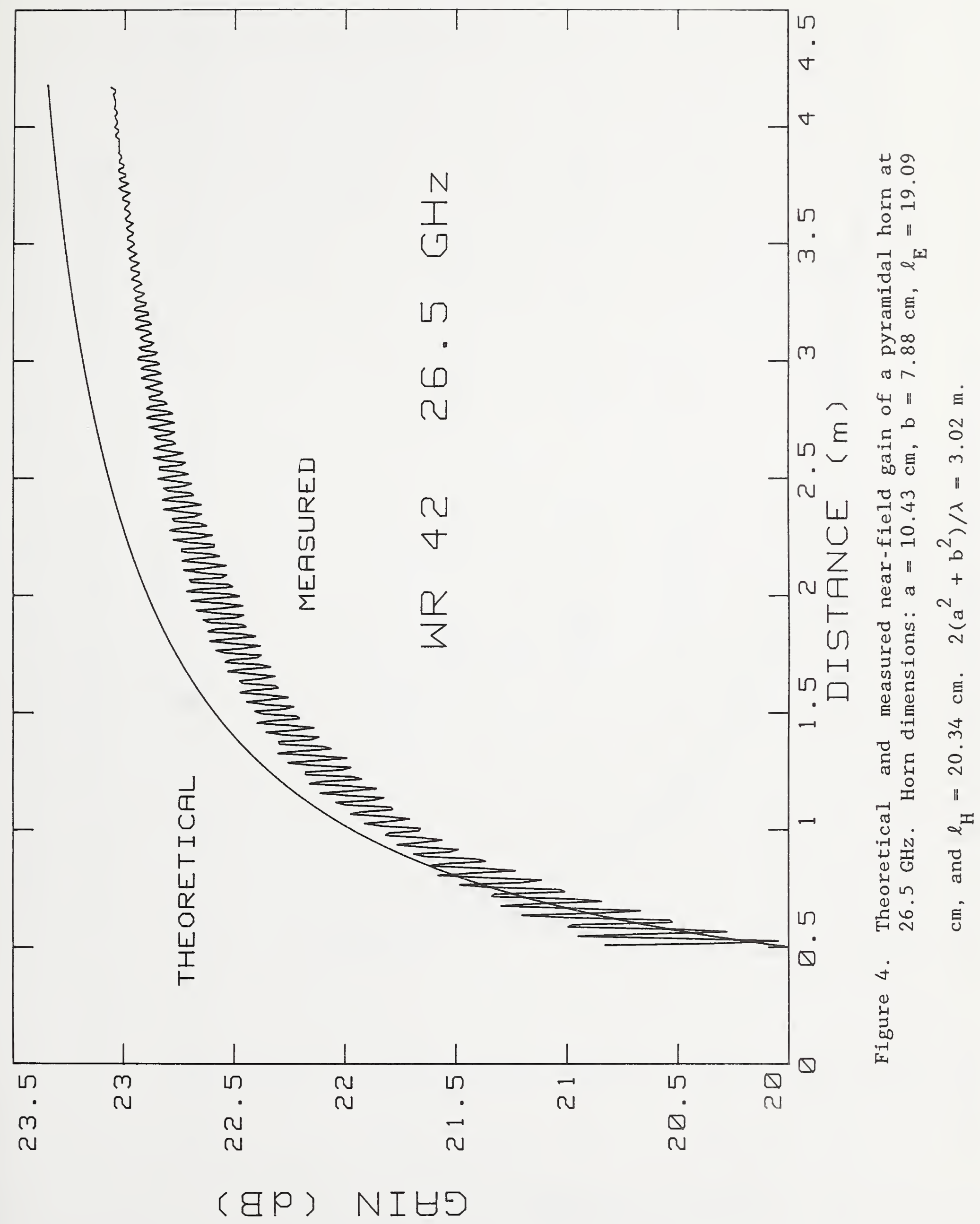




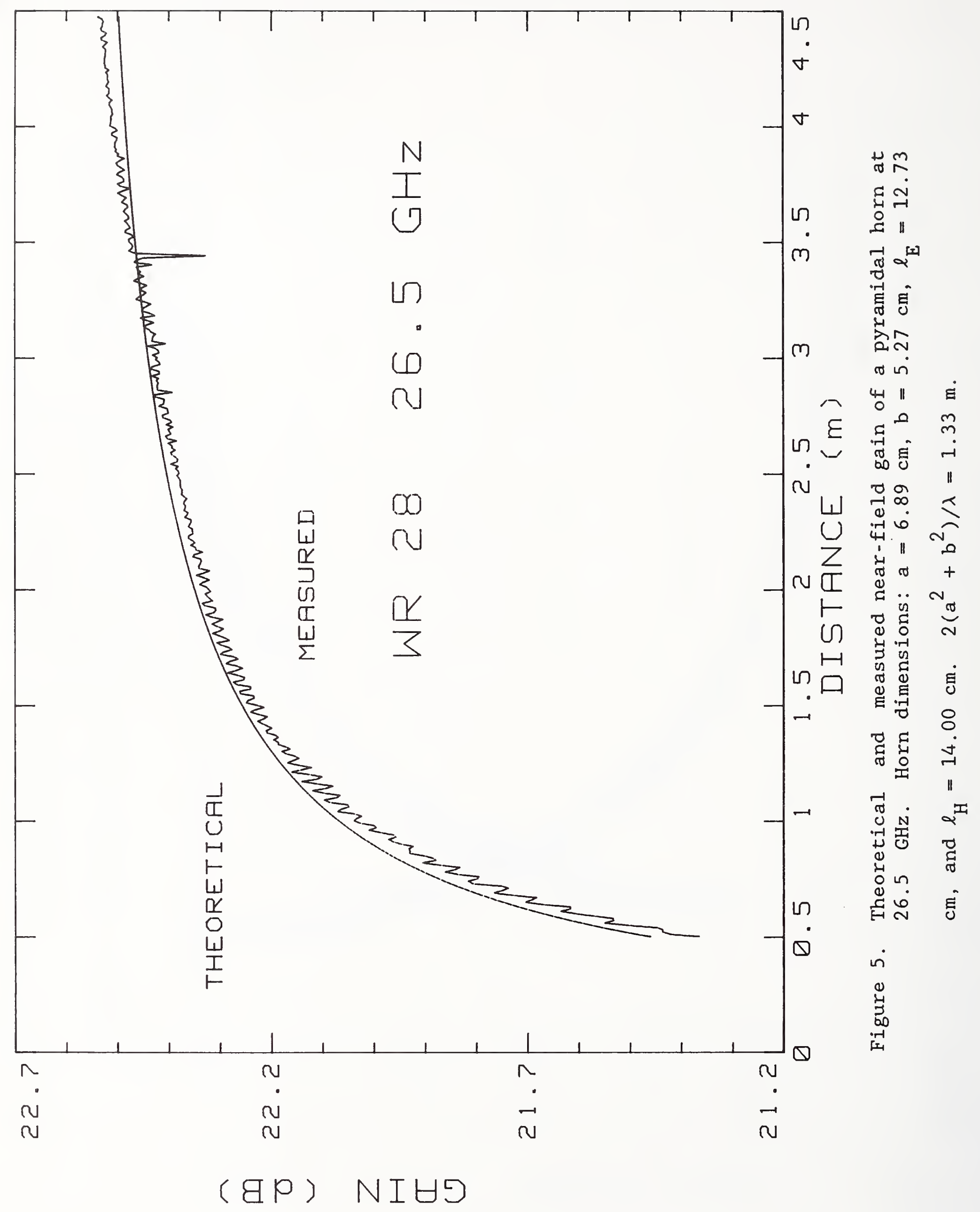




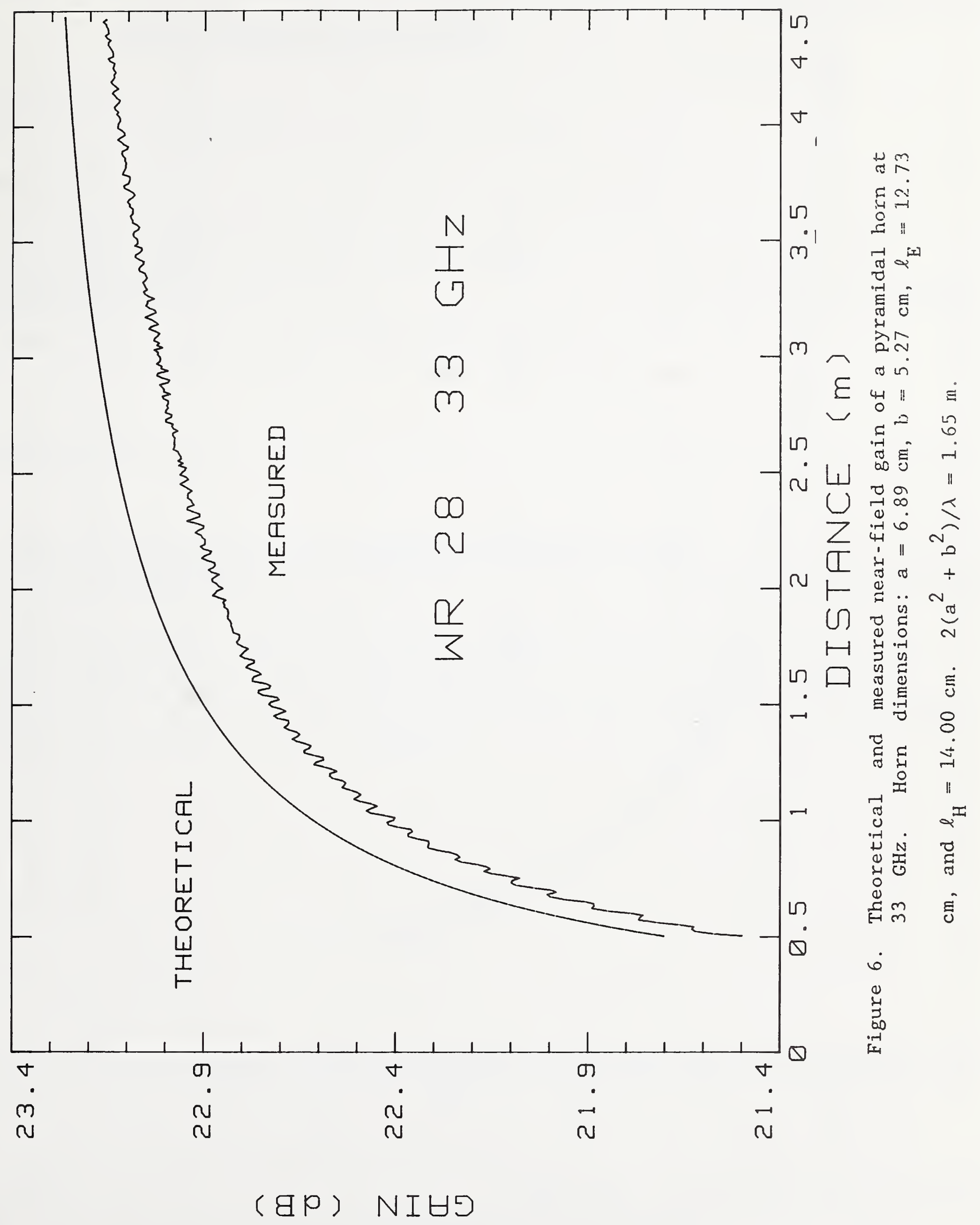




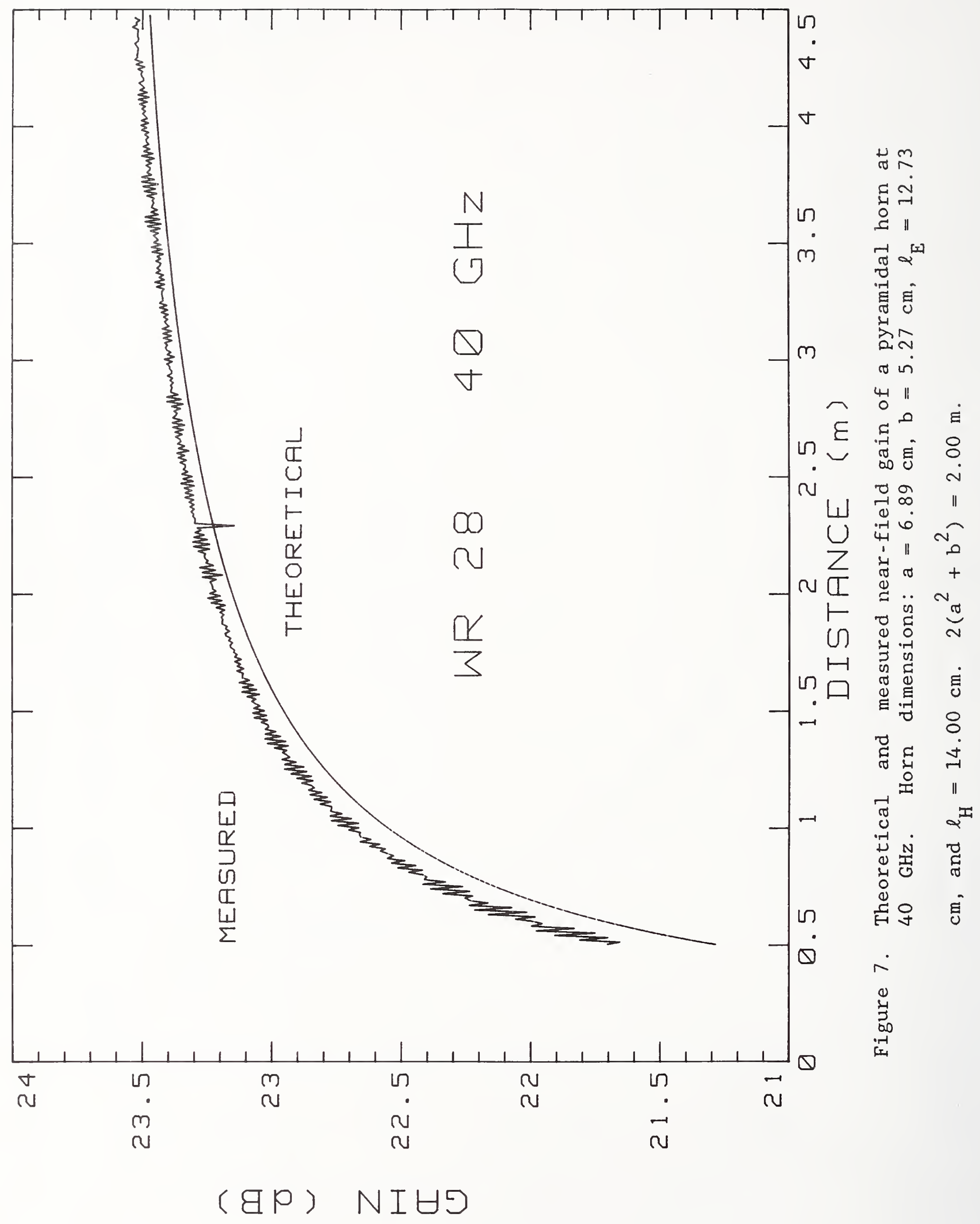


NIST-114A

(REV. 3-89)
U.S. DEPARTMENT OF COMMERCE

NATIONAL INSTITUTE OF STANDARDS AND TECHNOLOGY

BIBLIOGRAPHIC DATA SHEET
1. PUBLICATION OR REPORT NUMBER

NISTIR 89-3924

2. PERFORMING ORGANIZATION REPORT NUMBER

3. PUBLICATION DATE

November 1989

4. TITLE AND SUBTITLE

Near-Field Gain of Pyramidal Horns from 18 to $40 \mathrm{GHz}$

5. AUTHOR(S)

David A. Hill and Richard L. Ehret

6. PERFORMING ORGANIZATION (IF JOINT OR OTHER THAN NIST, SEE INSTRUCTIONS)

U.S. DEPARTMENT OF COMMERCE

NATIONAL INSTITUTE OF STANDARDS AND TECHNOLOGY

GAITHERSBURG, MD 20899

7. CONTRACT/GRANT NUMBER

8. TYPE OF REPORT AND PERIOD COVERED

9. SPONSORING ORGANIZATION NAME AND COMPLETE ADDRESS (STAEET, CITY, STATE, ZIP)

10. SUPPLEMENTARY NOTES

DOCUMENT DESCRIBES A COMPUTER PROGRAM; SF-185, FIPS SOFTWARE SUMMARY, IS ATTACHED.

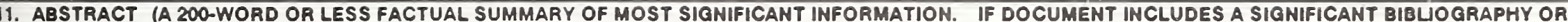
LITERATURE SURVEY, MENTION IT HERE.)

Generating a standard electromagnetic field requires knowledge of the gain of the transmitting antenna. Using the two-antenna method, we have measured the near-field gain of pyramidal horns at frequencies from 18 to $40 \mathrm{GHz}$. The discrepancy between the measured and theoretical near-field gain is typically within $\pm 0.3 \mathrm{~dB}$ for distances from 0.5 to $4 \mathrm{~m}$ from the horn aperture. An accurate laser alignment of the horns was necessary to obtain this level of agreement.

12. KEY WORDS (6 TO 12 ENTAIES; ALPHABETICAL ORDER; CAPITALIZE ONLY PROPER NAMES; AND SEPARATE KEY WORDS BY SEMICOLONS) anechoic chamber; electric field; near-field gain; pyramidal horn; two-antenna method

13. AVAILABILITY

$\mathrm{X}$ UNLMITED

FOR OFFICIAL DISTRIBUTION. DO NOT RELEASE TO NATIONAL TECHNICAL INFORMATION SERVICE (NTIS).

ORDER FROM SUPERINTENDENT OF DOCUMENTS, U.S. GOVERNMENT PRINTING OFFICE, WASHINGTON, DC 20402.

ORDER FROM NATIONAL TECHNICAL INFORMATION SERVICE (NTIS), SPRINGFIELD, VA 22161.

\section{ELECTRONIC FORM}






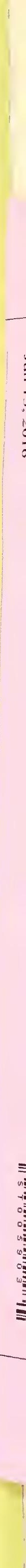

